\title{
TEKNIK PENGOLAHAN KOPI MENJADI SIRUP KOPI JAHE DI DESA KARANG SIDEMEN KECAMATAN BATUKLIANG UTARALOMBOK TENGAH
}

\author{
Suhaili $1^{*}$, Sulastri2, I Gusti Putu Muliarta Aryana3 \\ 1Program Studi Peternakan, Fakultas Peternakan Universitas Mataram \\ 2Program Studi PGSD FKIP Universitas Mataram \\ ${ }_{3}$ Fakultas Pertanian Universitas Mataram \\ ${ }^{*}$ Co-Author : Suhailiel371@gmail.com
}

\begin{abstract}
ABSTRAK. Desa Karang Sidemen adalah salah satu desa yang bertempat di kecamatan Batukliang Utara kabupaten Lombok Tengah. Desa ini merupakan salah satu desa yang mempunyai potensi di bidang pertanian. Di desa ini, sebagian besar masyarakatnya berprofesi sebagai petani sisanya sebagian kecil sebagai pegawai negeri dan swasta. Terdapat lebih dari $75 \%$ petani Desa Karang Sidemen mengelola komoditi Kopi ( Robusta ). Sisanya mengelola komoditi lain seperti, kacang panjang, durian, alpukad, rambutan, pisang, dan pepaya.Jumlah komoditi kopi terbilang sedikit, hal ini disebabkan karena kurangnya pemahaman petani dalam pengelolaan kopi sehingga banyak masyarakat desa karang sidemen yang menebang pohon kopinya.Mengacu pada permasalahan ini, dirasa penting untuk memberikan penyuluhan tentang nilai ekonomis kopirobusta jika berhasil diolah menjadi sirup kopi jahe yang memiliki cita rasa yang khas.Di samping itu, penyuluhan terkait pembuatan sirup kopi jahe diharapkan dapat meningkatkan kreativitas masyarakat desa karang sidemen, sehingga dengan adanya inovasi ini masyarakat dapat meningkatkan perekonomian dan menciptakan mata pencaharian yang baru.
\end{abstract}

Kata Kunci: Kopi Robusta, Sirup Kopi Jahe, Perekonomian

ABSTRACT. Karang Sidemen is one of the villages located in Batukliang Utara subdistrict, Central Lombok. This village has potential in agriculture. In this village, most of the people work as farmers, the rest are mostly public and private employees. There are more than $75 \%$ of the farmers in Karang Sidemen Village who manage the coffee commodity (Robusta). While the rest manage other commodities such as long beans, durian, avocado, rambutan, banana, and papaya. The number of coffee commodities is relatively small, this is due to the lack of understanding of farmers in coffee management so many villagers cut down their coffee trees. Referring to this problem, it is considered important to provide counseling on the economic value of Robusta coffee if it is successfully processed into ginger coffee syrup that has a distinctive taste. In addition, counseling related to the manufacture of ginger coffee syrup is expected to increase the creativity of the Karang Sidemen community, so that with this innovation the community can improve the economy and create a new livelihoods.

Keyword: Robusta Coffee, Ginger Coffee Syrup, Economy 


\section{PENDAHULUAN}

Kopi merupakan komoditi perkebunan penting bagi Desa Karang Sidemen, karena desa Karang Sidemen merupakan salah satu Desa yang memproduksi kopi. Jenis kopi yang banyak diusahakan di Desa Karang Sidemen adalah jenis Robusta dan Arabika. Dari kedua jenis kopi tersebut, Robusta lebih mudah ditanam, hasil produksinya lebih besar daripada Arabika, harga lebih murah daripada jenis Arabika. Oleh karena itu di Desa Karang Sidemen hanya memproduksi jenis kopi Robusta. Pemanfaatan kopi saat ini kebanyakan diolah menjadi minuman, dengan berbagai macam jenis merek yang beredar di pasar. Kebanyakan dari produk tersebut berupa kopi instant dengan penambahan gula, susu, lemak nabati (krimmer). Konsumsi kopi masih tergolong sangat rendah, yaitu 800 gram per orang pertahun, walaupun masyarakat Desa Karang Sidemen termasuk kelompok orang yang menyukai minuman kopi. Masyarakat perkotaan menjadikan seduhan kopi panas sebagai minuman favorit nomor dua setelah teh panas. Oleh karena itu perlu dikembangkan inovasi produk olahan kopi baru dengan citarasa yang lain, diharapkan dapat meningkatkan jumlah konsumsi kopi.

Pengembangan produk olahan kopi yang dapat dilakukan adalah dengan membuat sirup kopi jahe yang mempunyai citarasa yang menghangatkan. Berbagai macam produk minuman dapat dibuat menggunakan bahan dasar kopi, hal ini dikarenakan kopi mempunyai citarasa khas dan efek menyegarkan, tetapi agak pahit. Santoso HB, (1989). Menyatakan bahwa Jahe juga memberikan aroma tertentu untuk memenuhi selera seseorang dengan efek menyegarkan dan menghangatkan badan. Dengan menggabungkan kopi dan jahe yang mempunyai senyawa aktif hampir sama, maka dimungkinkan akan menimbulkan citarasa campuran yang dapat disenangi konsumen.

Seberapa banyak perbandingan kopi dan jahe sehingga perlu dikembangkan supaya dapat menghasilkan minuman dari kopi dan jahe yang memberikan kesegaran khusus dan baik bagi kesehatan. Pencampuran kopi dan jahe dapat menghasilkan citarasa yang pas dengan selera konsumen. maka pada kegiatan KKN Tematik Unram ini akan dilakukan percobaan pembuatan sirup dengan campuran kopi dan jahe dengan berbagai variasi perbandingan, sehingga dapat ditentukan perbandingan yang dapat mendekati kesukaan konsumen (Herman, 2003)

\section{METODE}

\section{Waktu danTempat}

Program ini dilaksanakan pada tanggal 23 Desember sampai 6 Februari 2020. Bertempat di Desa Karang Sidemen, Kecamatan Batukliang Utara, Kabupaten Lombok Tengah. Desa Karang Sidemen memiliki 14 (Empat Belas) dusun yakni Dusun Karang Sidemen Atas, Karang Sidemen Bawah, Sintung Barat, Sintung Timur, Sintung Utara, Mertak Paok, Pagutan, Selojan, Persil, Sintung Barat Dua, Sintung Barat Satu, Sintung Utara, Selojan,Jeliman.

\section{Alat dan Bahan}

Adapun alat-alat yang digunakan dalam pembuatan produk olahan SIKOPJA (Sirup Kopi Jahe) yaitu: (1) Kompor; (2) Wajan tanah liat; (3) Panci; (4) Sendok; (5) Baskom; (6) Spatula; (7) Pisau; (8) Ayakan; (9) Belender; (10) Timbangan; (11) Botol Kemasan; ; (12) Kertas stiker; dan (13) Talenan.

Sedangkan bahan - bahan yang digunakan yaitu: (1) Biji kopi; (2) Jahe; (3) Gula pasir; dan (4) Air. 


\section{Prosedur Pembuatan Produk Olahan SIKOPJA}

Prosedur pembuatan Sirup Kopi Jahe yang dilakukan oleh Mahasiswa KKN Tematik Universitas Mataram dengan tema produk olahan adalah sebagai berikut :

1. Menyiapkan alat dan bahan

2. Menyiapkan kopi yang sudah dipilih dan jahe yang sudah dikupas $1 \mathrm{~cm}$.

3. Menyangraikopi dan jahe hingga mengeluarkan aroma yang kuat dan didiamkan selama 24 jam.

4. Menghaluskan kopi yang sudah disangrai dan didiamkan selama 2 jam.

5. Memanaskan bubuk kopi jahe yang sudah dihaluskan dan dibiarkan hingga suhu menjadi dingin

6. Menyaring bubuk kopi jahe yang sudah dipanaskan untuk memisahkan ampas kopi jahe dan larutannya.

7. Menambahkan gula pada larutan kopi jahe kemudian dipanaskan lagi dan diaduk sampai agak mengental dan dibiarkan beberapa menit hingga suhu menjadi dingin.

8. Melakukan pengemasan SIKOPJA ( Sirup Kopi Jahe ).

9. Melakukan pemasaran melalui via online dan ofline

\section{HASIL DAN PEMBAHASAN}

\section{Persiapan program}

Pada tahap ini, pertama kali yang dilakukan adalah mengkomunikasikan rencana kegiatan kepada kepala desa terkait dengan waktu pelaksanaan, tempat dan meminta saran tentang kegiatan yang akan dilaksanakan khususnya yang berkaitan dengan peserta. Kemudian yang dilakukan adalah mencari refrensi untuk kegiatan sosialisasi. Pada kegiatan ini, tim melakukan sosialisasi dengan cara mendatangi beberapa rumah warga sebagai sample di masing - masing dusun.

\section{Pembuatan Sirup Kopi Jahe}

Setelah tahap pertama selesai, dihari $\mathrm{H}$ sebelum sosialisasi dilaksanakan, tim mulai membuat Sirup Kopi Jahe untuk nanti langsung dicicipi oleh sasaran sosialisasi. Selanjutnya, Sirup Kopi Jahe yang sudah dikemas dalam botol kemasan, ditempelkan stiker yang memuat merk dari Sirup Kopi Jahe yang sudah jadi.
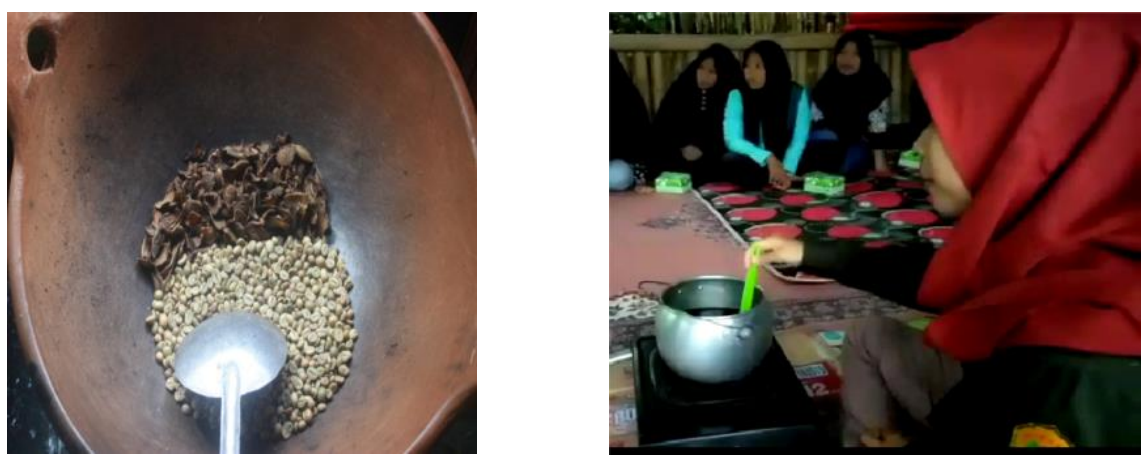

Gambar 1. Pembuatan Sirup Kopi Jahe 


\section{Sosialisasi dan Testimony}

Pada hari $\mathrm{H}$, tim mengunjungi rumah-rumah di tiap dusun untuk melakukan sosialisasi sekaligus testimony serta mengumpulkan data terkait respon masyarakat terhadap kegiatan yang sedang berlangsung dan juga sosialisasi tentang nilai ekonomis dari Sirup kopi tersebut.

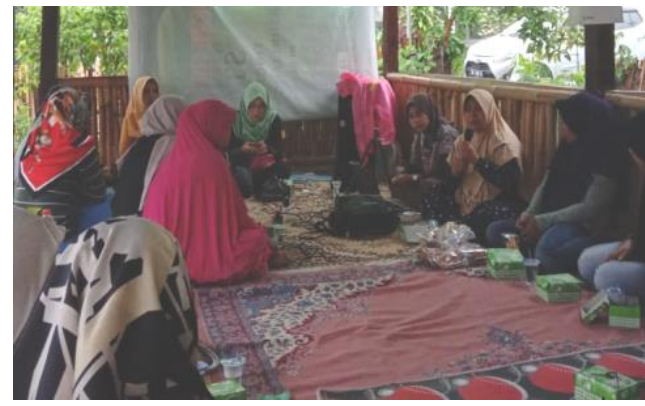

Gambar 2. Sosialisasi dan Testimony

\section{Pelatihan dan penyuluhan Sirup Kopi Jahe}

Kegiatan pertama dimulai dengan pembuatan Sirup Kopi Jahe. Pembuatan Sirup ini dilaksanakan Batukliang Utara sehari sebelum dilaksanakan penyuluhan dan testimoni. Pembuatan ini dilakukan oleh anggota KKN. Pembuatan ini memakan waktu kurang lebih 2 jam dalam sehari untuk Sirup Kopi Jahe sebanyak 6 botol. Selanjutnya, pembuatan stiker untuk merek Sirup yaitu "Sirup Kopi Jahe". kegiatan ini sebagai tahap percobaan untuk besoknya dilakukan penyuluhan dan menjadi bahan testimony untuk mengetahui tanggapan masyarakat terkait produk yang dibuat. Adapun kendala dalam kegiatan ini adalah kurangnya biji kopidikarnakan petani kopi yang mulai langka, sehingga pembuatan Sirup Kopi Jahe hanya bisa dilakukan dalam jumlah yang sedikit.

Selanjutnya, setelah dilakukan pembuatan Sirup Kopi Jahe, anggota KKN mengunjungi rumah-rumah warga di tiap dusun untuk melakukan penyuluhan sekaligus testimony kepada masyarakat terkait rasa Sirup Kopi Jahe yang sudah dibuat sekaligus mengumpulkan data terkait tanggapan masyarakat yang mencoba rasa sirup yang dibuat. Kegiatan ini adalah untuk memberikan pengetahuan kepada masyarakat khususnya Kelompok Wnita Tani (KWT) yang ada di Desa Karang Sidemen tentang teknik pengolahan biji kopi menjadi Sirup Kopi Jahe yang siap digunakan serta memiliki pangsa pasar yang cukup bagus, sekarang ini Desa Karang Sidemen menjadi salah satu tujuan wisatawan baik lokal maupun asing, sehingga diharapkan menjadi salah satu alternatif dalam peningkatan perekonomian masyarakat. Rumah-rumah yang dikunjungi sebanyak kurang lebih lima rumah untuk masing - masing dusun. Mereka terlihat begitu antusias dengan kegiatan penyuluhan dan testimony ini. Sesekali mereka memotong penjelasan kami dengan pertanyaan - pertanyaan seputar pembuatan Sirup Kopi Jahe. Dari kegiatan ini, masyarakat yang menjadi peserta akhirnya mengetahui cara pembuatan Sirup Kopi Jahe. Beberapa diantara mereka mengatakan akan mempraktikan untuk membuat Sirup Kopi Jahe ini sebagai olahan untuk kebutuhan rumah tangga agar bisa menghemat apabila ingin membeli sirup. Adapun kendala dalam kegiatan ini adalah ada beberapa peserta yang terkesan acuh tak acuh dengan kegiatan ini sehingga diharapkan peserta yang antusias bisa memberikan contoh dan menjadi umpan balik bagi peserta yang acuh tersebut. 


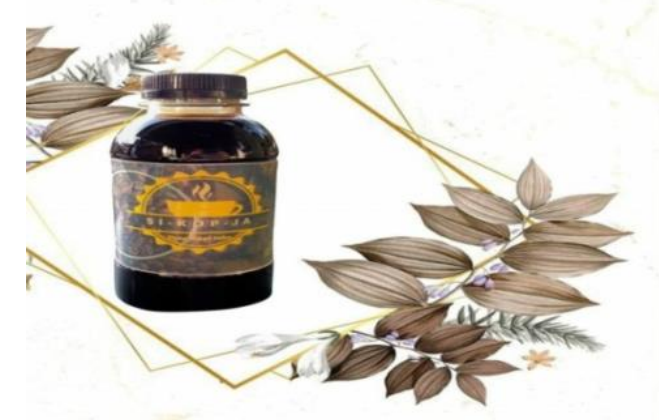

Hasil dari penuyuluhan Sirup Kopi Jahe yang sebelumnya tidak ingin menanam kopi akan memiliki keinginan untuk menanamnya, karena di wilayah Karng Sidemen sangat sedikit masyarakat yang menanam kopii. Setelah melakukan penyuluhan Sirup Kopi jahe, masyarakat jadi tahu bagaimana cara mengelola kopi agar memiliki nilai tambah ekonomis yang lebih tinggi. Selain itu, ibu-ibu rumah tangga bisa mendapatkan penghasilkan tanpa harus ke sawah. Sirup Kopi Jahe ini akan menjadi produk khas dari Wilayah Batukliang Utara terutama desa Karang Sidemen. Di Karang Sidemen terkenal dengan banyak wisatawan yang masuk sehingga dengan sirup ini akan menjadi daya tarik bagi wisatawan, karena seperti yang diketahui bahwa wisatawan terbiasa dengan makanan ringan seperti keripik pisang dan sebagainya dan akan lebih nikmat apabila disandingkan dengan Sirup dalam hal ini adalah Sirup Kopi Jahe (James dan Spillane, 2006).

Tabel 1. Break Even Point (BEP) Sirup Kopi Jahe

\begin{tabular}{lll}
\hline \multicolumn{1}{c}{ Bahan } & \multicolumn{1}{c}{ Satuan } & \multicolumn{1}{c}{ Harga } \\
\hline Biji Kopi & 500 gram & Rp. 20.000 \\
\hline Jahe & 500 gram & Rp. 25.000 \\
\hline Gula Pasir & $1,5 \mathrm{~kg}$ & Rp. 18.000 \\
\hline Botol Kemsaan & $16 \times 1000$ & Rp. 16.000 \\
\hline Air & 3 Liter & Rp. 10.000 \\
\hline Kertas Stiker & 3 Lembar & Rp. 4.500 \\
\hline Total & & Rp. 93.500
\end{tabular}

$1 \mathrm{~kg}$ bubuk kopi jahedapat menghasilkan 16 botol sirup dengan kapasitas $200 \mathrm{ml}$ menggunakan botol plastik, Sirup Kopi Jahe ini dijual dengan harga Rp. 10.000,00 per botol.

\section{Analisis SWOT}

SWOT adalah metode perencanaan strategis yang digunakan untuk mengevaluasi faktor faktor yang berpengaruh dalam usaha untuk mencapai tujuan, yaitu kekuatan (strengths), kelemahan (weaknesses ), peluang ( opportunities ), dan ancaman (threats) dalam suatu spekulasi bisnis. Keempat faktor itulah yang membentuk akronim SWOT (strengths, weaknesses, opportunities, dan threats) SWOT baik diterapkan dalam jangka waktu panjang maupun jangka waktu pendek ( Gomez K.A 1984 ).

Metode analisis ini tujuannya adalah untuk menggambarkan situasi dan kondisi yang sedang dihadapi dan bukan merupakan alat analisis yang dapat memberikan solusi terhadap masalah yang 
telah dihadapi. Analisis SWOT sangat berperan penting dalam bisnis karena tujuannya untuk membuat kerangka situasi dalam suatu bisnis maupun perusahaan. Berikut pnnjelasan dari masing - masing unsur tersebut.

Kekuatan (Strenghts) : (1) Meningkatnya nilai tambah dari biji kopi dan Menambah perekonomian mayarakat; (2) Dapat menjadi produk ciri khas dari daerah Karang Sidemen; \& (3) Produk higienis tanpa pengawet dan pemanis buatan.

Kelemahan (Weaknesses) Belum mampu bersaing dengan produk kopi lainnya dengan skala besar. Peluang (Opportunities) : (1) Segmen pasar yang jelas; (2) Menjadi inovasi produk baru di desa Karang Sidemen. Ancaman (Threats) Pesaing dengan produk kopi yang lain

\section{Pemasaran Produk}

Pemasaran dilakukan dengan 2 teknik yaitu Konvensional \&Online. Dalam pemasaran kami memasarkannya melalui seperti pameran, care free day, dan toko - toko yang ada di lombok tengah khususnya Batukliang Utara Desa Karang Sidemen. Dalam pemasaran online kami menjual melalui media sosial seperti Facebook, Instagram, Twitter.

\section{KESIMPULAN}

Dari hasil pembuatan sirup kopi jahe ini menghasilkan citarasa yang khas dan setelah masyarakat mengetahui rasa dari sirup kopi jahe ini masyarakat desa karang sidemen terutama Kelompok Wanita Tani sangat berantusias ingin membuat produk kopi yang sudah kami ajarkan yaitu Sirup Kopi Jahe (SIKOPJA).

Citarasa sirup kopi jahe dapat diterima oleh masyarakat karang sidemen, tetapi untuk masa lama penyimpanan atau kadalwarsa sirup kopi jahe belum diketahui, sehingga perlu dilakukan penelitian lebih lanjut untuk mengetahui daya simpan sirup kopi jahe.

\section{REFERENSI}

Gomez, K.A. and A. A. Gomez, 1984. Statistical Procedurs for Agricultural Research.2nd Edition. John Wiley and Sons,New-York. Herman. 2003. Membangkitkan Kembali Peran Komoditas Kopi Bagi Perekonomian.Indonesia. Bogor. Insitut Pertanian Bogor. James dan Spillane J. 2006 Komoditi Kopi Robusta: Peranannya dalam Perekonomian. Indonesia. Yogyakarta: Kanisius. Mulato, S. dan E. Suharyanto, 2012.Kopi Seduhan dan Kesehatan.Pusat Penelitian kopi dan Kakao Indonesia.Jember. Santoso HB. 1989. Jahe. Penerbit Kanisius. Yogyakarta.

Sarpian T. 2003. Pedoman Berkebun Kopi dan Analisis Usaha Tani. Penerbit Kanisius, Yogyakarta. 